\title{
Laparoscopic resection of a tumor in the descending colon cancer associated with Crohn's disease: a case report
}

\author{
Shinsuke Kazama ${ }^{1}$, Tomomichi Kiyomatsu ${ }^{1}$, Teppei Morikawa ${ }^{2}$, Satomi Yoneyama ${ }^{1}$, Toshiaki \\ Tanaka $^{1}$, J unichiro Tanaka ${ }^{1}$, Kazushige Kawai ${ }^{1}$, Hironori Yamaguchi ${ }^{1}$, Hiroaki Nozawa ${ }^{1}$, \\ Takamitsu Kanazawa ${ }^{1}$, Soichiro I shihara ${ }^{1}$, Eiji Sunami ${ }^{1}$, Toshiaki Watanabe $^{1}$ \\ 1. Division of Surgical Oncology, Department of Surgery, Faculty of Medicine, The University of Tokyo, Tokyo, Japan. \\ 2. Department of Pathology, Graduate School of Medicine, The University of Tokyo, Tokyo, Japan.
}

Correspondence: Shinsuke Kazama, M.D. Address: Division of Surgical Oncology, Department of Surgery, Faculty of Medicine, The University of Tokyo, 7-3-1 Hongo, Bunkyo-ku, Tokyo, 113-8655, Japan. E-mail: kaz-tky@umin.ac.jp

Received: July 30, 2014

Accepted: September 19, 2014

Online Published: October 20, 2014

DOI : $10.5430 /$ crcp.v2n1p55

URL: http://dx.doi.org/10.5430/crcp.v2n1p55

\section{Abstract}

Background: Although patients with Crohn's disease are at an increased risk of cancer, surveillance strategies and surgical guidelines for colorectal cancer that is associated with Crohn's disease have not been established.

Case report: We describe a 60-year-old man with a 30-year history of Crohn's disease within the large bowel who had been undergoing annual colonoscopic surveillance and presented with a tumor in the descending colon. An elevated mass lesion that occupied the intestinal lumen was not detected until one year after his last surveillance procedure. A biopsy of the lesion revealed high-grade dysplasia, and immunohistochemistry showed that the lesion was positive for tumor protein p53. We suspected cancer in the descending colon as a complication of Crohn's disease and performed a laparoscopicassisted left hemicolectomy. Histologically, this patient had stage II colon cancer.

Conclusion: An accumulation of case reports that describe Crohn's disease in association with cancer will help to establish suitable surveillance strategies and surgical procedures. Therefore, the need for surveillance to manage patients with Crohn's disease must be discussed in the future.

\section{Key words}

Crohn’s disease, Colon cancer, Surveillance colonoscopy

\section{I ntroduction}

Colorectal cancer is a serious complication of inflammatory bowel disease. Indeed, patients with long-standing ulcerative colitis are at a high risk of developing colorectal cancer ${ }^{[1]}$. However, colorectal cancer associated with Crohn's disease (CD) is not well understood. Although some meta-analyses describe an increased incidence of colorectal cancer in patients with CD, the risk factors for colorectal cancer associated with CD have not been established ${ }^{[2,3]}$. Moreover, the necessity for surveillance recommendations and a surgical strategy for colorectal cancer associated with CD have been highlighted. 
As the number of patients with CD has risen in Japan, it has become increasingly common for patients to be diagnosed with colorectal cancer that is associated with CD. However, Japanese patients reportedly differ from patients in westernized countries with respect to the characteristics of colorectal cancer as a complication of CD. Anorectal lesions are the most frequently encountered lesions in Japanese patients with colorectal cancer that is associated with $\mathrm{CD}^{[4]}$. Moreover, there are few descriptions of Japanese patients presenting with colon cancer as a complication of CD in the medical literature.

In the current case report, we describe a 60-year-old male patient in whom cancer of the descending colon developed 30 years after the onset of CD. The patient had been undergoing annual colonoscopic surveillance. He was diagnosed with colon cancer near a stricture of the descending colon, and he underwent laparoscopic curative surgery.

\section{Case report}

A 60-year-old male patient presented with a 30-year history of CD that affected the large bowel. The patient had responded well to treatment with sulfasalazine and had not required steroids or immunosuppressive drugs. The patient had been undergoing colonoscopic surveillance annually. Since 2009, however, it had not been possible to perform colonoscopic examinations of the total area of the large bowel because of the presence of a stricture within the descending colon that was caused by severe inflammation associated with CD. In 2012, colonoscopy did not reveal any masses in the area from the stenosis of the descending colon to the rectum, and examination of biopsy specimens taken from the lesion near the stricture showed inflammation associated with CD, but no evidence of malignancy. In 2013, the patient suffered from severe abdominal pain that was caused by ileus, and his condition improved with conservative management. Moreover, colonoscopy detected an elevated mass lesion in the distal area of the stricture. The patient was referred to our hospital for further examination.

The patient's medical history prior to his diagnosis of CD included surgery for cholelithiasis at the age of 31 years. The patient had no family history of inflammatory bowel disease or colorectal cancer. At the time of hospitalization, the patient did not have abdominal pain and was not producing watery diarrhea that contained blood. Blood tests did not reveal anemia, and tumor marker levels, including those of the carcinoembryonic antigen, cancer antigen 19-9, and serum p53 antibody, were normal at 2.2 (normal range, 0-5.0 mg/ml), 25 (normal range, 0-37.0 U/ml), and 0.4 (normal range, 0-1.3 $\mathrm{U} / \mathrm{ml}$ ), respectively. A pinhole stenosis of the descending colon was identified by colonoscopy that had not been detected by fiberscopy. Moreover, an elevated mass lesion was detected on the anal side of the stenosis in the descending colon that measured approximately $30 \mathrm{~mm}$ (see Figure 1). A biopsy of the lesion revealed high-grade dysplasia, and immunehistochemical staining showed that the lesion was positive for tumor protein p53, which is characteristic of dysplasiaassociated lesions or masses ${ }^{[5]}$. Computed tomography imaging revealed a thickening of the wall of the descending colon without any swelling of the lymph nodes, or lung or liver metastases.

Figure 1. Colonofiberscopy demonstrated the elevated mass lesion of approximately 30 $\mathrm{mm}$ on the anal side of the stenosis of the descending colon.

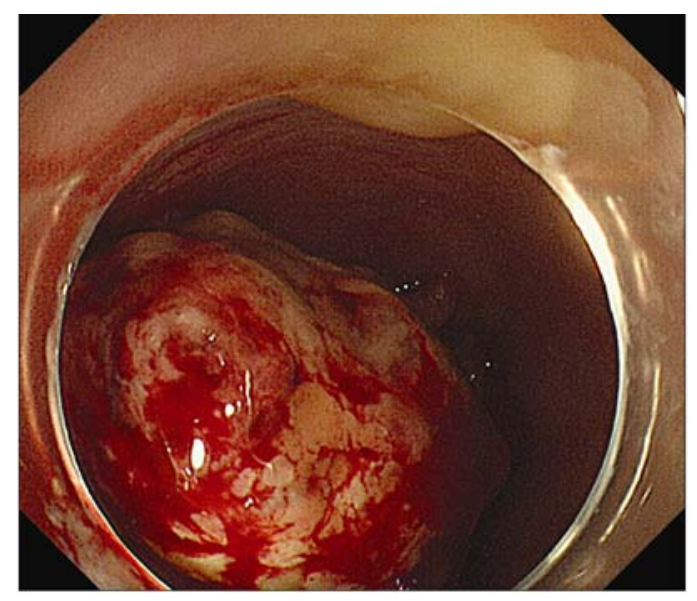

ISSN 2331-2726 E-ISSN 2331-2734 
Thus, with a suspected diagnosis of cancer of the descending colon as a complication of $\mathrm{CD}$, we performed a laparoscopic-assisted left hemicolectomy. Macroscopically, the tumor measured $5.0 \mathrm{~cm} \times 3.5 \mathrm{~cm}$, and it was a well-circumscribed, elevated mass lesion with ulceration (see Figure 2). Microscopically, the tumor was a mucinous adenocarcinoma that had invaded the subserosa (see Figure 3A). Abundant mucin production was apparent in approximately $80 \%$ of the tumor area. Immunohistochemical staining showed that the cancerous lesion was positive for tumor protein p53 (see Figure 3B). High-grade dysplasia was present within the surface mucosa of the elevated lesion, but not in the flat mucosa around the lesion. Neither lymphovascular invasion nor regional lymph node metastases were detected. Thus, the pathological stage of the tumor was PT3 N0. The patient's postoperative recovery proceeded reasonably well, and he was discharged from our hospital 17 days after being admitted. No recurrence of the tumor was observed 10 months after surgery.

Figure 2. Macroscopic appearance of the descending colon cancer (black arrow). Note the stenosis of the descending colon and wall thickness with ulceration distal to the stenosis.
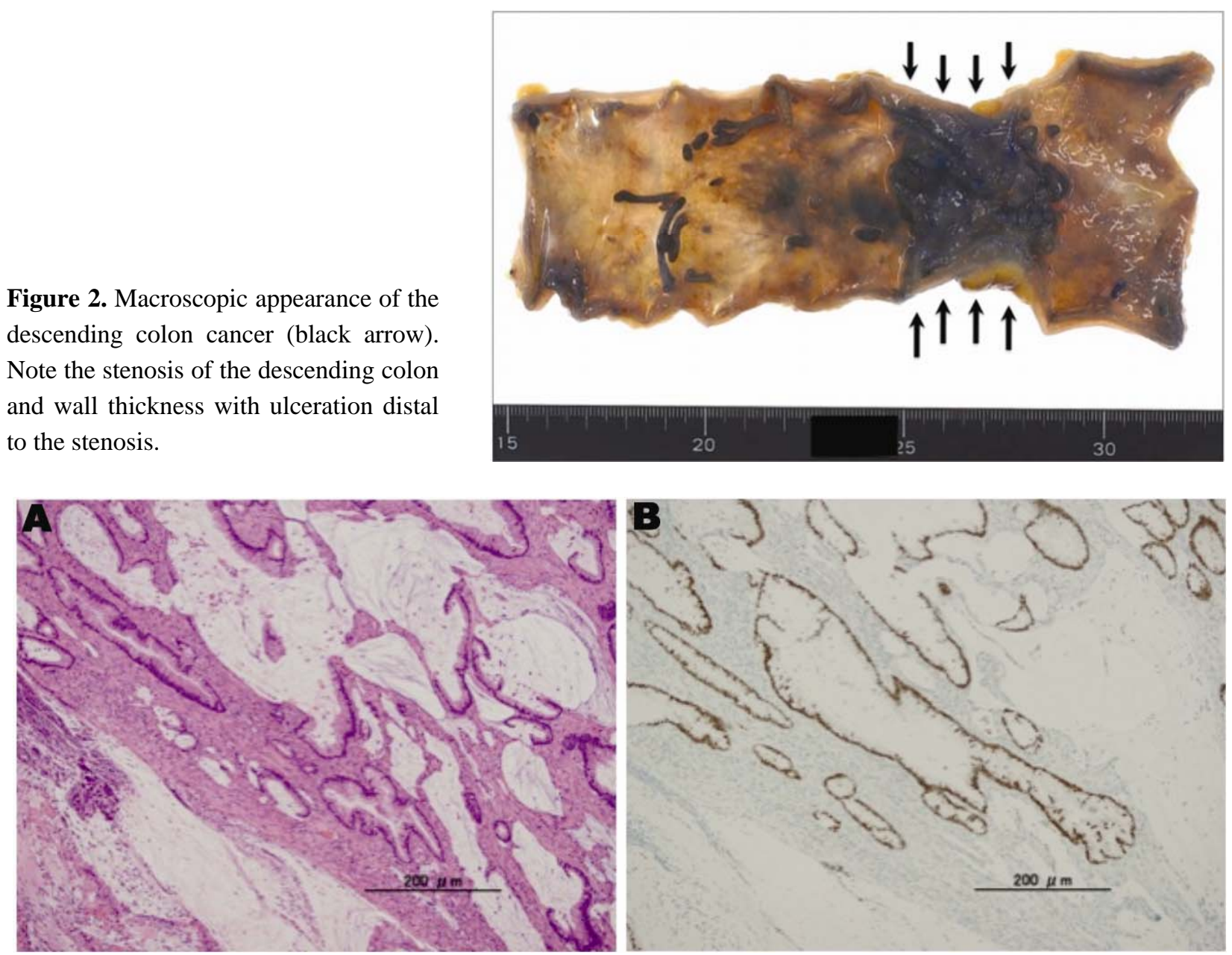

Figure 3. (A) The tumor showed well-differentiated adenocarcinoma consistent with mucinous adenocarcinoma invading to the subserosa (original magnification, $\times 100$ ). (B) The tumor diffusely positive for p53 immunohistochemical staining (original magnification, $\times 100$ ).

\section{Discussion}

We have described a male patient with cancer of the descending colon as a complication of CD that affected the large bowel. The patient had been undergoing annual colonoscopic surveillance. The stenosis of the descending colon that was caused by severe inflammation and was associated with $\mathrm{CD}$ had been detected by colonoscopy four years earlier. The 
lesion near the stenosis had not revealed any macroscopic or histopathologic abnormalities. However, the elevated mass lesion that occupied the intestinal lumen was not identified until one year after the last surveillance procedure.

In recent years, the association between $\mathrm{CD}$ and a high risk of intestinal cancers has been recognized, as it has been for ulcerated colitis. Published meta-analyses have shown that the overall relative risk of colorectal cancer in patients with CD is 2.5 (95\% confidence interval [CI], 1.3-4.7), while in patients with colonic disease it is 4.5 (95\% CI, 1.3-14.9) ${ }^{[2]}$. Another meta-analysis reported a higher relative risk of colorectal cancer in patients with $\mathrm{CD}$ compared with the baseline population (2.4 [95\% CI, 1.56-4.36]) ${ }^{[3]}$. In Japan, it is becoming increasingly common for patients to be diagnosed with anorectal cancer in association with CD, and the number of patients being diagnosed with CD is rising. An analysis of 770 patients with CD in Japan determined that the standardized incidence ratio was 2.79 (95\% CI, 1.28-5.29) for colorectal cancer, and that it was significantly higher, by approximately 2.8-fold, in the CD group compared with the healthy population ${ }^{[6]}$. Hence, there is a higher risk of patients developing colorectal cancer in association with CD in Japan, which concurs with findings in westernized countries. However, the characteristics of the colorectal cancers that present as complications in Japanese patients with CD differ from those seen in patients from westernized countries. Case reports describe many of the intestinal cancers that are associated with CD as small bowel cancers that are associated with fistulas, as well as cancers of the rectum and anal canal ${ }^{[4]}$. Comparatively few reports have described colon cancer as a complication of CD in Japan; therefore, the case we have described is relatively rare in Japan. The table presents the clinicopathological characteristics of nine Japanese patients who presented with colon cancer as a complication of CD and whose case reports have been published in the literature since $2000^{[7-13]}$. Stenotic lesions were detected in six cases (67\%), and mucinous carcinomas were diagnosed in five cases (56\%).

Table. Recent reports of colonic cancer in Japanease patients complicated with CD

\begin{tabular}{|c|c|c|c|c|c|c|c|c|c|c|c|c|c|}
\hline & Author & Year & Age & Gender & $\begin{array}{l}\text { CD } \\
\text { duration }\end{array}$ & $\begin{array}{l}\text { Type of } \\
\text { CD }\end{array}$ & $\begin{array}{l}\text { Primary } \\
\text { site }\end{array}$ & $\begin{array}{l}\text { TNM } \\
\text { stage }\end{array}$ & Stenosis & $\begin{array}{l}\text { Histologi } \\
\text { c type }\end{array}$ & Dysplasia & $\begin{array}{l}\text { p53 } \\
\text { immunohist } \\
\text { ochemistry }\end{array}$ & $\begin{array}{l}\text { Clinical } \\
\text { outcome }\end{array}$ \\
\hline 1 & $\begin{array}{l}\text { Kagaya } \\
\text { T et al. }{ }^{\left[{ }^{[7]}\right.}\end{array}$ & 2001 & 56 & F & NS & Colon & Ascending & $\begin{array}{l}\text { T3N0 } \\
\text { M0 }\end{array}$ & Yes & well & NS & NS & $\begin{array}{l}\text { 2Y4M } \\
\text { Alive }\end{array}$ \\
\hline 2 & $\begin{array}{l}\text { Yao }{ }^{\mathrm{T}} \\
\text { et al. }{ }^{[8]}\end{array}$ & 2002 & 62 & F & $37 Y$ & Ileocolon & Sigmoid & T4M1 & Yes & muc, por & No & Positive & 1M Dead \\
\hline 3 & $\begin{array}{l}\text { Nagao } \\
\mathrm{M} \text { et al. } \\
\text { [9] }\end{array}$ & 2004 & 29 & M & $1 \mathrm{Y}$ & NS & Descnding & $\begin{array}{l}\text { T3N0 } \\
\text { M0 }\end{array}$ & Yes & well, muc & Yes & Positive & $\begin{array}{l}\text { 1Y5M } \\
\text { Alive }\end{array}$ \\
\hline 4 & $\begin{array}{l}\text { Shikano } \\
\mathrm{T} \\
\text { et al. }{ }^{[10]}\end{array}$ & 2006 & 46 & $\mathrm{~F}$ & NS & NS & Sigmoid & $\begin{array}{l}\text { T2N0 } \\
\text { M0 }\end{array}$ & Yes & well & No & NS & $\begin{array}{l}\text { 2Y6M } \\
\text { Alive }\end{array}$ \\
\hline 5 & $\begin{array}{l}\text { Uza } \mathrm{N} \\
\text { et al. }{ }^{[11]}\end{array}$ & 2006 & 32 & M & $17 Y$ & NS & Cecum & NS & No & muc, sig & Yes & NS & $\begin{array}{l}\text { 2Y5M } \\
\text { Alive }\end{array}$ \\
\hline 6 & $\begin{array}{l}\text { Hayashi } \\
\mathrm{T} \\
\text { et al. }{ }^{[12]}\end{array}$ & 2007 & 46 & M & $9 \mathrm{Y}$ & Ileocolon & Ascending & T4M0 & No & muc & NS & NS & 5M Dead \\
\hline 7 & $\begin{array}{l}\text { Hayashi } \\
\mathrm{T} \text { et al. } \\
{[13]}\end{array}$ & 2007 & 33 & $\mathrm{~F}$ & $16 \mathrm{Y}$ & Ileocolon & Transverse & $\begin{array}{l}\text { T3N0 } \\
\text { M0 }\end{array}$ & No & muc & NS & NS & 7M Alive \\
\hline 8 & $\begin{array}{l}\text { Araki Y } \\
\text { et al. }{ }^{[14]}\end{array}$ & 2009 & 34 & M & $2 \mathrm{Y}$ & Colon & Sigmoid & $\begin{array}{l}\text { T3N0 } \\
\text { M0 }\end{array}$ & Yes & well & Yes & NS & 3M Dead \\
\hline 9 & $\begin{array}{l}\text { Present } \\
\text { case }\end{array}$ & 2013 & 60 & M & $30 \mathrm{Y}$ & Colon & Descnding & $\begin{array}{l}\text { T3N0 } \\
\text { M0 }\end{array}$ & Yes & muc & Yes & Positive & $\begin{array}{l}10 \mathrm{M} \\
\text { Alive }\end{array}$ \\
\hline
\end{tabular}

The reported risk factors for colon cancer in patients with longstanding CD include the extent of the disease, the duration of the illness, the presence of anal lesions, the presence of fistulas, the presence of a bypassed segment, and complications associated with sclerosing cholangitis ${ }^{[14]}$. CD-associated colorectal adenocarcinoma is diagnosed at an average age of 48 years, which is 10-15 years younger than the average age at which sporadic colorectal cancers are diagnosed ${ }^{[15]}$. The median disease duration before colorectal cancer is detected in patients with CD is 18.5 years. Kyle et al. proposed that patients who develop colonic cancer could be divided into two groups according to their background with one group containing younger patients with a long history of $\mathrm{CD}$ and the other group containing older patients with a short history of 
$\mathrm{CD}^{[16]}$. Given that the patient we have described did not suffer from anal fistulas, had a long history of $\mathrm{CD}$, and the onset of carcinogenesis was recent, our case appears to belong to the first group.

Surveillance colonoscopy is a routine procedure for patients with long-standing ulcerative colitis, and patients with CD who have a high risk of developing cancer, which includes those with extensive colonic disease that has been present from a young age, have been recommended for surveillance colonoscopy ${ }^{[3,17]}$. However, despite the growing body of evidence that describes the potential for patients with long-standing CD to develop cancer, specific guidelines for surveillance have yet to be defined. The British Society for Gastroenterology's surveillance guidelines recommend that surveillance should begin from 8 to 10 years after the onset of colonic CD, which is based on the evidence that relates to ulcerative colitis ${ }^{[18]}$. Although the patient described in this case report had been undergoing annual colonoscopic surveillance for an extended period of time, the cancerous lesion was not detected at an early stage. Therefore, patient management might be improved by performing obligatory endoscopic surveillance to identify precancerous dysplasias in patients with $\mathrm{CD}$, because colonoscopy can be troublesome for these patients. In addition, examinations can be painful if disease-associated colonic or anal strictures are present. An accumulation of case reports that describe CD in association with cancer will help to establish suitable surveillance strategies. Therefore, the need for surveillance to manage patients with CD must be discussed in the future.

The standard treatment for ulcerative colitis-associated cancer is total proctocolectomy. However, in patients with colorectal cancer as a complication of CD, the indication for total proctocolectomy is controversial ${ }^{[19,20]}$. We performed a laparoscopic-assisted left hemicolectomy on the patient whose case is described here, because dysplasia was not detected either close to or distant from the cancerous lesion. Several studies have reported high rates of metachronous colon cancer after segmental resections of colon cancers that presented as complications in $\mathrm{CD}^{[21]}$. Studies with larger sample sizes are required to determine whether total proctocolectomies should be considered for patients with cancer associated with CD.

In conclusion, we have reported a relatively rare case of cancer within the descending colon that was associated with CD in a patient who had been undergoing annual colonoscopic surveillance and who underwent laparoscopic surgery. Colorectal cancer associated with CD is rare, and a clearly defined surveillance strategy is not yet available. An accumulation of case reports is required to establish a surveillance strategy for CD-associated cancer.

\section{References}

[1] Eaden JA, Abrams KR, Mayberry JF. The risk of colorectal cancer in ulcerative colitis: a meta-analysis. Gut. 2001; 48(4): 526-535. PMid: 11247898. http://dx.doi.org/ 10.1136/gut.48.4.526

[2] Canavan C, Abrams KR, Mayberry JF. Meta-analysis: mortality in Crohn's disease. Aliment Pharmacol Ther. 2007; 25(1): 861-870. PMid: 17402989. http://dx.doi.org/ 10.1111/j.1365-2036.2007.03276.x

[3] Von Roon AC, Reese G, Teare J, Constantinides V, Darzi AW, Tekkis PP. The risk of cancer in patients with Crohn's disease. Dis Colon Rectum. 2007; 50(6): 839-855. PMid: 17308939.

[4] Yano Y, Matsui T, Uno H, Hirai F, Futami K, Iwashita A. Risks and clinical features of colorectal cancer complicating Crohn's disease in Japanese patients. J Gastroenterol Hepatol. 2008; 23(11): 1683-1688. PMid: 18752557.

http://dx.doi.org/10.1111/j.1440-1746.2008.05532.x

[5] Loddenkemper C. Diagnostic standards in the pathology of inflammatory bowel disease. Dig Dis. 2009; 27(4): 576-583. Epub 2009 Nov 4. Review. PMid: 19897978. http://dx.doi.org/10.1159/000233301

[6] Yano Y, Matsui T, Hirai F, Okado Y, Sato Y, Tsurumi K, et al. Cancer risk in Japanese Crohn's disease patients: investigation of the standardized incidence ratio. J Gastroenterol Hepatol. 2013; 28(8): 1300-1305. PMid: 23488881. http://dx.doi.org/10.1111/jgh.12189

[7] Kagaya T, Shimamura Y, Ishii M, Yoshitake O, Fujita S, Takayama S, et al. Colon cancer in Crohn’s disease: A Case Report. Jpn J Gastroenterol Surg. 2001; 34(6): 637-641. http://dx.doi.org/10.5833/jjgs.34.637

[8] Yao S, Iwashita A, Nishimura T, Motomura A, Furukawa H, Wada Y, et al. Clinicopathological and Immunohistochemical Features of the colorectal carcinomas, complicating Crohn's disease. [Article in Japanese] Stomach and Intestine. 2002; 37(8): 1047-1058. 
[9] Nagao M, Funayama Y, Fukushima K, Shibata C. A case of Crohn’s disease complicated with colonic cancer. [Article in Japanese] Jpn J Gastroenterol Surg. 2004; 37: 1492-1502. http://dx.doi.org/10.5833/jjgs.37.1497

[10] Shikano T, Koshikawa K, Taniguchi K, Kiriyama K. Colonic cancer arising in Crohn’s disease. [Article in Japanese] J Jpn Surg Assoc. 2006; 67(2): 382-386. http://dx.doi.org/10.3919/jjsa.67.382

[11] Uza N, Nakase H, Kuwabara Y, Fujii S, Chiba T. Caecal cancer associated with longstanding Crohn's disease. Lancet. 2006 Nov 18; 368(9549): 1842. PMid: 17113433. http://dx.doi.org/10.1016/S0140-6736(06)69741-9

[12] Hayashi T, Nakamura T, Kurachi K, Fukazawa A, Nakajima A, Nakamura K, et al. Crohn's disease-associated colorectal cancer in Japan: report of four cases. Int J Colorectal Dis. 2007 Dec; 22(12): 1537-1542. Epub 2007 Aug 24. PMid: 17717673. http://dx.doi.org/10.1007/s00384-007-0371-2

[13] Araki Y, Yoshioka K, Iwamoto S, Yamaki S, Iwai A, Nakane Y, et al. A case of colon cancer associated with Crohn's Colitis, Appeared in a very short disease duration [Article in Japanese] Jpn J Gastroenterol Surg. 2009; 42(10): 1597-1602. http://dx.doi.org/10.5833/jjgs.42.1597

[14] Sjodahl RI, Myrelid P, Soderholm JD. Anal and rectal cancer in Crohn's disease. Colorectal Dis. 2003; 5(5): 490-495. PMid: 12925087. http://dx.doi.org/ 10.1046/j.1463-1318.2003.00510.x

[15] Rubio CA, Befrits R. Colorectal adenocarcinoma in Crohn's disease: a retrospective histologic study. Dis Colon Rectum. 1997; 40(9): 1072-1078. PMid: 9293938.

[16] Kyle J, Ewen SW. Two types of colorectal carcinoma in Crohn's disease. Ann R Coll Surg Engl. 1992; 74(6): 387-390. PMid: 1471833.

[17] Friedman S, Rubin PH, Bodian C, Goldstein E, Harpaz N, Present DH. Screening and surveillance colonoscopy in chronic Crohn's colitis. Gastroenterology. 2001; 120(4): 820-826. PMid: 11231935. http://dx.doi.org/ 10.1053/gast.2001.22449

[18] Mowat C, Cole A, Windsor A, Ahmad T, Arnott I, Driscoll R, et al. Guidelines for the management of inflammatory bowel disease in adults. Gut. 2011; 60(5): 571-607. PMid: 21464096.

[19] Andersson P, Olaison G, Hallbook O, Sjodahl R. Segmental resection or subtotal colectomy in Crohn's colitis? Dis Colon Rectum. 2002; 45(1): 47-53. PMid: 11786764.

[20] Kiran RP, Nisar PJ, Goldblum JR, Fazio VW, Remzi FH, Shen B, et al. Dysplasia associated with Crohn's colitis: segmental colectomy or more extended resection? Ann Surg. 2012; 256(2): 221-226. PMid: 22791098. http://dx.doi.org/ 10.1097/SLA.0b013e31825f0709

[21] Maser EA, Sachar DB, Kruse D, Harpaz N, Ullman T, Bauer JJ. High rates of metachronous colon cancer or dysplasia after segmental resection or subtotal colectomy in Crohn's colitis. Inflamm Bowel Dis. 2013; 19(9): 1827-1832. PMid: 23669402. http://dx.doi.org/ 10.1097/MIB.0b013e318289c166 